\title{
Isolation of TSCD11 Gene for Early Chloroplast Development under High Temperature in Rice
}

Guonan Fang, Shenglong Yang, Banpu Ruan, Chaolei Liu, Anpeng Zhang, Hongzhen Jiang, Shilin Ding, Biao Tian, Yu Zhang, Noushin Jahan, Li Zhu, Guangheng Zhang, Guojun Dong, Qiang Zhang, Dali Zeng, Longbiao Guo, Zhenyu Gao* (D) and Qian Qian*

\begin{abstract}
Background: Chloroplasts are essential for photosynthesis and play key roles in plant development. High temperature affects structure of chloroplasts and metabolism in plants. The seryl-tRNA synthetase plays an important role in translation of proteins. Although seryl-tRNA synthetase has been widely studied in microbes and animals, few studies have reported about its role in chloroplast development under high temperature in rice.

Results: In this study, we isolated a novel temperature-sensitive chlorophyll-deficient 11 (tscd11) mutant by ethyl methane sulfonate (EMS) mutagenesis of japonica variety Wuyujing7. The $t s c d 11$ mutant developed albino leaves at the 3-leaf stage under high temperature $\left(35^{\circ} \mathrm{C}\right)$, but had normal green leaves under low temperature $\left(25^{\circ} \mathrm{C}\right)$.

Consistent with the albino phenotype, impaired chloroplasts, decreased chlorophyll content and increased ROS accumulation were found in the tscd11 mutant at $35^{\circ} \mathrm{C}$. Fine mapping and DNA sequencing of tscd11 revealed a missense mutation ( $G$ to $A$ ) in the eighth exon of LOC_Os11g39670 resulted in amino acid change (Glu $u_{374}$ to Lys $\left._{374}\right)$. The TSCD11 gene encodes a seryl-tRNA synthetase localized to chloroplast. Complementation test confirmed that the point mutation in TSCD11 is responsible for the phenotype of tscd11. TSCD11 is highly expressed in leaves. Compared with the wild type (WT), mutation in TSCD11 led to significant alteration in expression levels of genes associated with chlorophyll biosynthesis, photosynthesis and chloroplast development under high temperature.

Conclusions: TSCD11, encoding a seryl-tRNA synthetase localized to chloroplast, is vital to early chloroplast development at high temperature in rice, which help to further study on the molecular mechanism of chloroplast development under high temperature.
\end{abstract}

Keywords: TSCD11, Seryl-tRNA synthetase, Temperature-sensitive, Chloroplast development, Rice

\section{Background}

Global warming poses many severe challenges to human life, for example, by dramatically reducing crop yields (Battisti and Naylor 2009; Bohra-Mishra et al. 2014; Lobell et al. 2011; Peng et al. 2004). In order to adapt to the harsh environment, plants have evolved multiple tolerance strategies (Bita and Gerats 2013). Under favorable

\footnotetext{
* Correspondence: zygao2000@hotmail.com; qianqian188@hotmail.com State Key Laboratory of Rice Biology, China National Rice Research Institute, Hangzhou 310006, China
}

\section{SpringerOpen}

temperature conditions, plants can perform photosynthesis and grow well. While facing extremely unfavorable temperature conditions, plants acclimate to stresses by fine-tuning gene expression in response to environments. Genomic and genetic evidence suggests that various proteins participate in plant thermal response (Jacob et al. 2017; Kumar and Wigge 2010).

Chloroplasts have the characteristics of distinguishing plant cells from animal cells. They are the organs necessary for photosynthesis of higher plants and are also responsible for biosynthesis and storage of various (c) The Author(s). 2020 Open Access This article is licensed under a Creative Commons Attribution 4.0 International License which permits use, sharing, adaptation, distribution and reproduction in any medium or format, as long as you give appropriate credit to the original author(s) and the source, provide a link to the Creative Commons licence, and indicate if changes were made. The images or other third party material in this article are included in the article's Creative Commons licence, unless indicated otherwise in a credit line to the material. If material is not included in the article's Creative Commons licence and your intended use is not permitted by statutory regulation or exceeds the permitted use, you will need to obtain permission directly from the copyright holder. To view a copy of this licence, visit http://creativecommons.org/licenses/by/4.0/. 
metabolites (Jensen and Leister 2014). The plastid and nuclear genome together control the formation of chloroplast from proplastid, this procedure is affected by environmental conditions such as light and temperature (López-Juez 2007; Mullet 1993). More and more evidence have revealed that chloroplast biogenesis is highly regulated. Photosystem II (PSII) is the least heatresistant component of the chloroplast thylakoid membrane, and heat stress induces dysfunction of the oxygen releasing complex by imposing sustained oxidative damage to the chloroplast (Allakhverdiev et al. 2008; Yang et al. 2019). In addition, thermal stress usually leads to the destruction of the overall structural integrity of chloroplast thylakoid membranes, especially destacking of thylakoid membranes, which eventually hampers chloroplast development (Semenova 2004; Yamamoto et al. 2008). Chloroplast is a semi-autonomous organelle that encodes about 100 genes (Delannoy et al. 2009). Mutations in these genes often result in a large number of macroscopic leaf-color mutants. Some genes have been cloned in rice so far including $M g$-chelatase $H$ subunit (OsCHLH), Virescent 1 (V1), Chlorophyll a Oxygenase (OsCAO1), Yellow Leaf and Early Flowering (YE1), Heat-stress Sensitive Albino 1 (HSA1), Virescent 2 (V2), Yellow-green Leaf 1 (YGL1), Virescent 3 (V3), Stripe1 (ST1) and Thermo-sensitive Chlorophyll-deficient Mutant 5 (TCM5) (Jung et al. 2003; Kusumi et al. 2011; Lee et al. 2005; Peng et al. 2019; Qiu et al. 2017; Sugimoto et al. 2007; Wu et al. 2007; Yoo et al. 2009; Zheng et al. 2016). Only minority of them are high temperature sensitive, including HSA1 and TCM5, which are considered to be ideal materials for studying the mechanisms underlie the response to heat stress during chloroplast development.

Aminoacyl-tRNA synthetases (AARSs) are essential enzymes for protein synthesis. The classical function of AARSs are to catalyze the connection of specific amino acids to the corresponding tRNA to form aminoacyl tRNA, then according to the principle that the anticodon of the tRNA matches the codon of the mRNA, the amino acids are sequentially connected on the ribosome to synthesize the protein. This reaction is the first step in protein synthesis (Banerjee et al. 2011; Pak et al. 2018). In plants, protein synthesis occurs in the cytoplasm, mitochondria and chloroplasts (Schimmel and Soll 1979). Although AARSs are highly conserved enzymes, they show diverse functions, such as splicing of RNA, participation in immune response and tRNA proofreading (Guo et al. 2010; Martinis et al. 1999; Szymański et al. 2000). Because amide-tRNA synthetase is critical in cells, mutants of AARSs are rarely reported. The edd 1 mutant with inactivated glycyl-tRNA synthetase in Arabidopsis, showed embryo-defective in development (Uwer et al. 1998). In Arabidopsis, the twn2 mutant had altered expression of valyl-tRNA synthetase and exhibited suspensor-derived polyembryony (Zhang and Somerville 1997). In rice, the wp1 mutant with a signal-nucleotide substitution in the gene coding for valtRNA synthetase, showed white stripe and albino phenotypes at the seedling stage, and white panicle phenotype at the heading stage, indicating its role in early chloroplast development in rice (Wang et al. 2016). Few of cloned AARSs genes have been reported to affect chloroplast development under high temperature. The sertyl-tRNA synthetase has been reported frequently in microbes and animals, however, rarely in plants. In order to study the cellular function of plant sertyl-tRNA synthetase, virus induced gene silencing (VIGS) was utilized to generate mutants with reduced expression of sertyltRNA synthetase in Nicotiana benthamiana, and a severe yellowing leaf phenotype was found. The number and size of chloroplasts, and chlorophyll content were also dramatically reduced in the mutants (Kim et al. 2005). The result indicated that sertyl-tRNA synthetase may play a key role in chloroplast development.

Although the seryl-tRNA synthetase has been widely studied in microbes and animals, few have been reported about its roles in chloroplast development under high temperature in rice. In this study, we identified a novel tscd11 mutant with sensitivity to high temperature. The mutant exhibited albino leaves phenotype at the 3-leaf stage at $35^{\circ} \mathrm{C}$, whereas had normal green leaves at $25^{\circ} \mathrm{C}$. Map-based cloning of the TSCD11 gene revealed it encoding seryl-tRNA synthetase, which is vital to chloroplast development under high temperature.

\section{Main Text}

\section{Results}

Phenotypes of the tscd11 Mutant in Different Environmental Temperatures

At the seedling stage, the tscd11 mutant plants exhibited different phenotypes with different sowing date in the paddy field. When the tscd11 mutant plants were sown in May, they developed white-striped leaves, and their contents of chlorophyll $a$ (Chl $a$ ), chlorophyll $b(\mathrm{Chl} b)$ and carotenoid (Car) were decreased by $23.2 \%, 34.6 \%$ and $14.8 \%$ compared to the wild-type plants, respectively (Fig. 1a, c). The leaves exhibited albino in the June sowing mutant plants, and their contents of $\mathrm{Chl} a$, Chl $b$ and Car in tscd11 were only $2.7 \%, 3.2 \%$ and $7.6 \%$ that of the wild-type plants, respectively (Fig. 1b, d). To test whether the phenotypic difference of $t s c d 11$ is affected by temperature, plants of the WT and tscd11 were treated with different temperatures in growth chambers. The tscd11 mutant showed almost the same phenotype as the WT at $25^{\circ} \mathrm{C}$, with similar Chl $a$ and Car contents (Fig. 1e, h). The tscd11 mutant exhibited yellowish green 

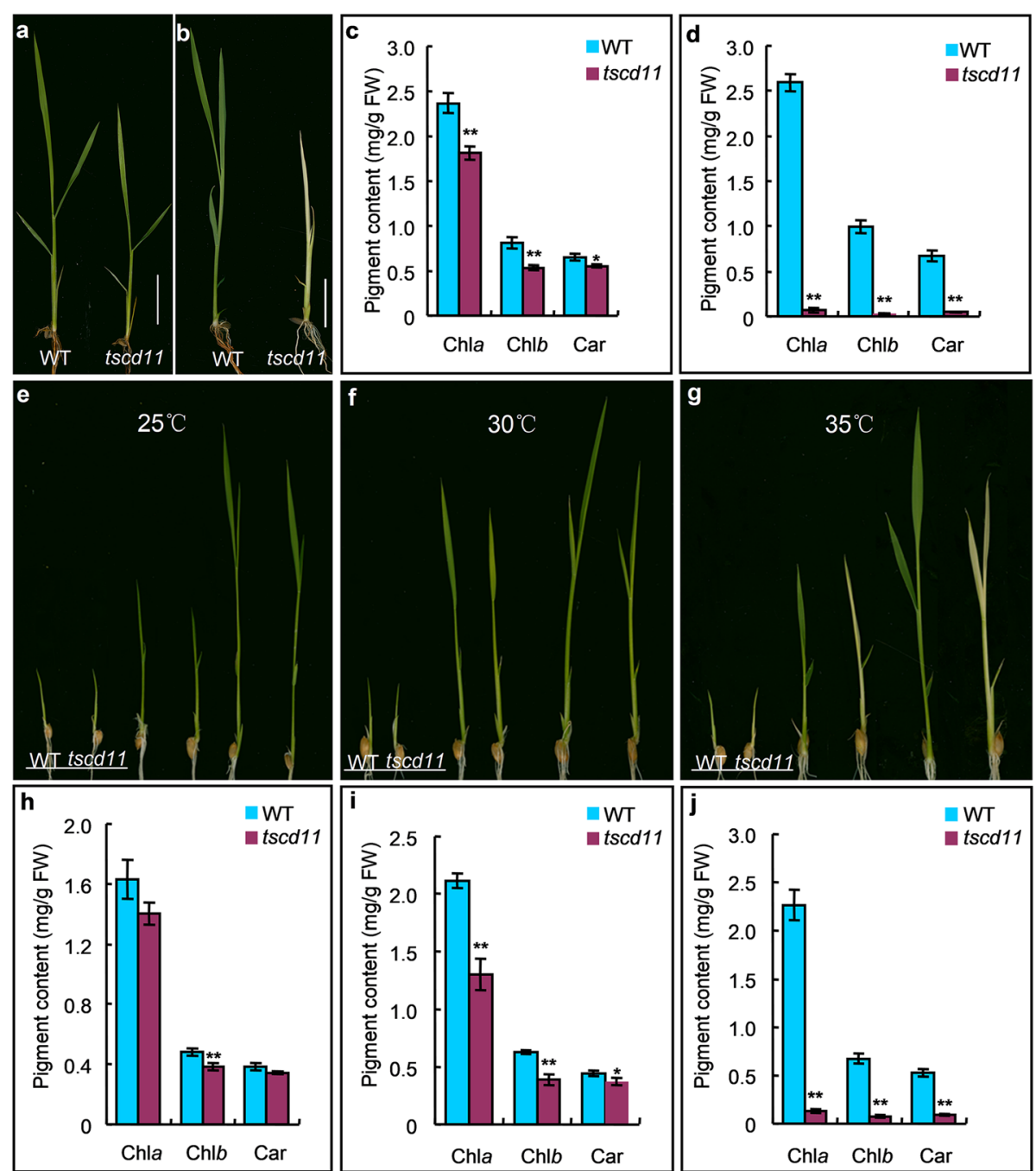

Fig. 1 Phenotypes and pigment contents comparison between wild-type and tscd11 plants. a-b Morphology of wild-type and tscd11 plants at the seedling stage sown in May and June, respectively, in the paddy field $(\mathrm{bar}=2 \mathrm{~cm}) \cdot \mathbf{c}-\mathbf{d}$ pigment contents of WT and tscd11 at the seeding stage in May and June, respectively. e-g 1-, 2-, 3-leaf stage seedlings of the WT and $\operatorname{tscd} 11$ mutant grown at $25^{\circ} \mathrm{C}, 30^{\circ} \mathrm{C}$ and $35^{\circ} \mathrm{C}$, respectively. h-j Pigment contents of 3-leaf stage of the wild-type and tscd11 plants grown at $25^{\circ} \mathrm{C}, 30^{\circ} \mathrm{C}$ and $35^{\circ} \mathrm{C}$, resepectively. Chl $a$, chlorphyll $a$; $\mathrm{Chl} b$, chlorphyll $b$; Car, carotenoids. Data represent mean $\pm \mathrm{SD}(n=3) .{ }^{*} p<0.05,{ }^{* *} p<0.01$ (Student's $t$-test)

phenotype at $30^{\circ} \mathrm{C}$ (Fig. 1f), with the contents of chlorophyll (Chl) decreased accordingly compared with the WT (Fig. 1i). At $35^{\circ} \mathrm{C}$, the tscd11 mutant displayed albino phenotype at the 3-leaf stage (Fig. 1g), and could not survive until the 4-5 leaf stage. The Chl $a$, Chl $b$ and Car were only $5.9 \%, 12.0 \%$ and $18.0 \%$ contents of the WT (Fig. 1j). Furthermore, as shown in Fig. 1g, the tscd11 mutant developed albino leaves from the 2-leaf stage at $35^{\circ} \mathrm{C}$. Therefore, we performed temperature shift experiments at the 2-leaf stage. As shown in Fig. S1f, the new third leaf of the tscd11 mutant showed albino phenotype when shifted from $25^{\circ} \mathrm{C}$ to $35^{\circ} \mathrm{C}$ at the 3-leaf stage, and the contents of Chl $a$, Chl $b$ and Car in tscd 11 were only 9.5\%, $16.9 \%$ and $20.6 \%$ that of the WT, respectively
(Additional file 1: Fig. S1f, j). While the new third leaf of $t s c d 11$ exhibited white-stripe leaf phenotype when shifted from $35^{\circ} \mathrm{C}$ to $25^{\circ} \mathrm{C}$ at the 3-leaf stage. And although the contents of Chl $a$, Chl $b$ and Car in $t s c d 11$ decreased significantly compared to the WT from $35^{\circ} \mathrm{C}$ to $25^{\circ} \mathrm{C}$, the pigment contents of $t s c d 11$ were significantly higher from $35^{\circ} \mathrm{C}$ to $25^{\circ} \mathrm{C}$ than those at $35^{\circ} \mathrm{C}$ (Additional file 1: Fig. S1g, h, k, l; Additional file 2: Table S1). Therefore, pigment synthesis in the $t s c d 11$ mutant is temperature dependent. Moreover, differences in pigment contents became smaller in the paddy field as climate temperature decreased from summer till fall (Additional file 1: Fig. S2) in Hangzhou of China. These results illustrate that the tscd11 mutant is sensitive to high temperature. 
In addition, agronomic traits of the WT and tscd11 plants were investigated in the paddy field. Compared with the WT, plant height, panicle length, seed-setting rate and 1000-grain weight were significantly decreased in tscd11, indicating the mutation also inhibits plant growth (Additional file 2: Table S2).

\section{Chloroplast Development Is Hampered in the tscd11 Mutant under High Temperature}

The chloroplast ultra-structure of the WT and the tscd11 mutant were observed at the 3-leaf stage by transmission electron microscopy (TEM). The chloroplast ultra-structure of $t s c d 11$ changed little at $25^{\circ} \mathrm{C}$ (Fig. 2ab, e-f). By contrast, chloroplasts were observed impaired without stacked grana or stromal thylakoids in tscd11 compared with the WT at $35^{\circ} \mathrm{C}$ (Fig. 2c, d, g-h). These results suggest that mutation hampered chloroplast development in the tscd11 mutant under high temperature.

\section{More ROS Accumulation in the tscd11 Mutant under High Temperature}

Increased accumulation of reactive oxygen species (ROS) usually occurs in weak plants under high temperature (Chen et al. 2017; Chen et al. 2018). To verify this hypothesis, we performed 3, 3'-diaminobenzidine (DAB) staining and nitro blue tetrazolium (NBT) staining tests to detect hydrogen peroxide $\left(\mathrm{H}_{2} \mathrm{O}_{2}\right)$ and superoxide anions $\left(\mathrm{O}_{2}^{-}\right)$, two indicators of ROS. Numerous $\mathrm{H}_{2} \mathrm{O}_{2}$ and $\mathrm{O}_{2}{ }^{-}$accumulated in the albino leaves of $t s c d 11$ grown at $35{ }^{\circ} \mathrm{C}$ (Additional file 1: Fig. S3a, b, f, g). We then measured contents of senescence-related substances, $\mathrm{H}_{2} \mathrm{O}_{2}$ and malondialdehyde (MDA), and catalase (CAT) activity at $25^{\circ} \mathrm{C}$ and $35^{\circ} \mathrm{C}$. Contents of $\mathrm{H}_{2} \mathrm{O}_{2}$ and MDA increased, and CAT activity decreased in tscd11 compared to the WT at $25^{\circ} \mathrm{C}$, however, the differences did not reach significant levels (Additional file 1: Fig. S3c-e). In contrast, contents of $\mathrm{H}_{2} \mathrm{O}_{2}$ and MDA significantly increased, and CAT activity significantly decreased in tscd11 compared to the WT at $35^{\circ} \mathrm{C}$ (Additional file 1: Fig. S3h-j). These results were consistent with the staining results with $\mathrm{DAB}$ and NBT, indicating that the mutation results in more ROS accumulation in the tscd11 mutant under high temperature stress. Due to significant differences in peroxide levels between the WT and the $t s c d 11$ mutant at high temperature, we measured transcriptional expression of some senescence related genes including WRKY transcription factor (WRKY72), Osh36, Stay Green Rice (SGR), ROS-responsive genes WRKY transcription factor (WRKY24, WRKY70), and detoxification related genes Alternative Oxidase (AOX1a, AOX1b), Ascorbate Peroxidase (APX1), Catalase (CATB) and Superoxide Dismutase (SODA1, SODB) in the tscd11 and wild-type plants. At $25^{\circ} \mathrm{C}$, the transcript levels of most senescence, ROS-responsive and detoxification related genes showed no significant difference between the wild-type and tscd11 plants (Additional file 1: Fig. S3k). While at $35^{\circ} \mathrm{C}$, the transcript levels of all tested genes were significantly higher in $t s c d 11$ plants than those in the wild-type plants (Additional file 1: Fig. S3l). To examine cell death in tscd11 at molecular level, the top leaves from the wild-type and tscd11 plants at the 3-leaf stage were subjected to the terminal deoxynucleotidyl transferase-mediated dUTP nick-end labeling (TUNEL) assay according to the method of Huang et al. (2007). The same leaf sections were synchronously stained with

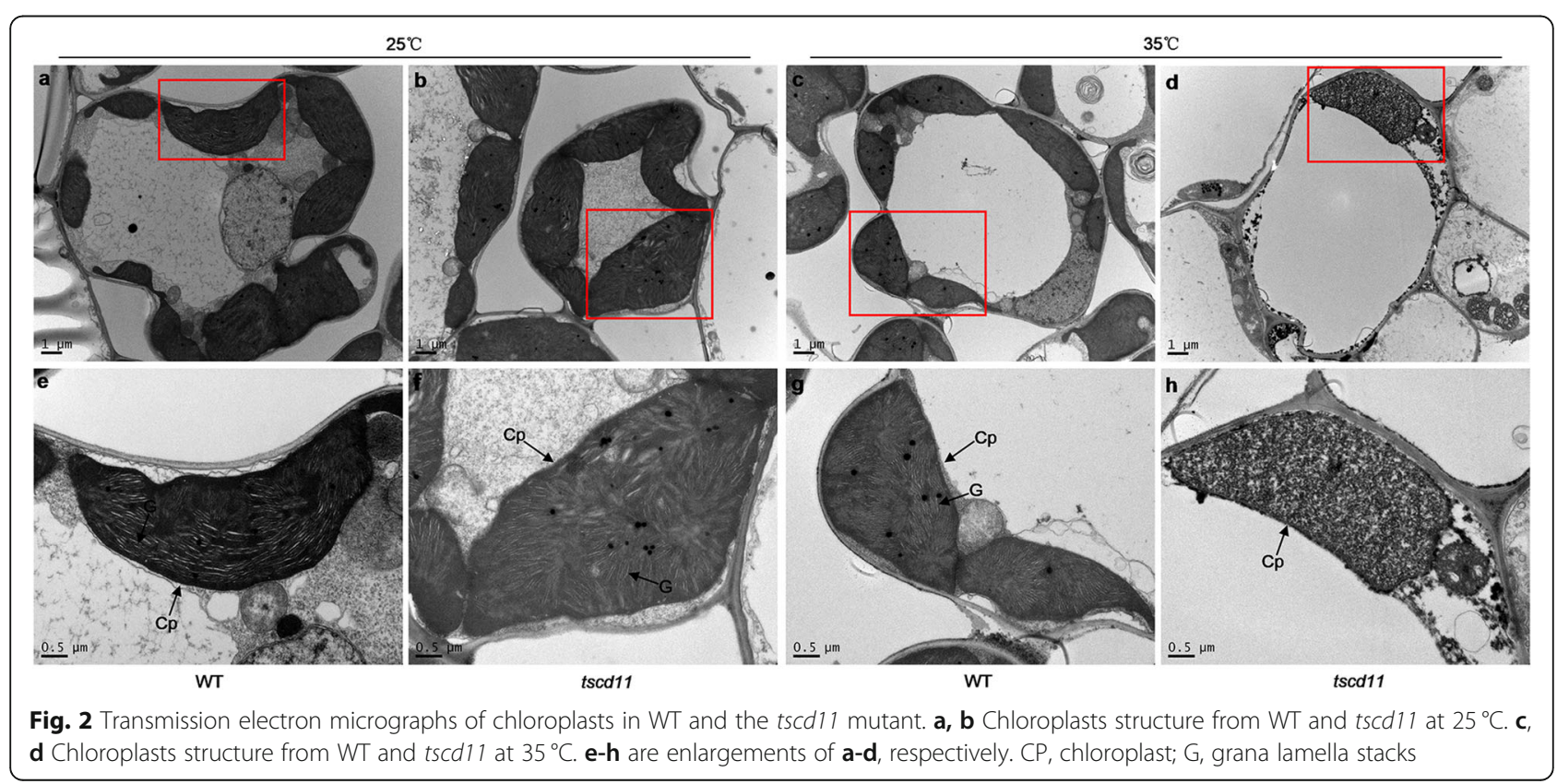


propidium iodide (PI) to indicate nuclei (red) in each section. Fewer nuclei were TUNEL positive in the WT grown at $25^{\circ} \mathrm{C}$ or $35^{\circ} \mathrm{C}$ and tscd 11 grown at $25^{\circ} \mathrm{C}$; On the contrary, more nuclei in tscd11 showed TUNEL positive compared with the WT (Additional file 1: Fig. S4). The result reveals that the mutation affects DNA stability in the tscd11 mutant under high temperature.

\section{Genetic Analysis and Map-Based Cloning of TSCD11}

Genetic analysis of reciprocal crosses were performed between the tscd11 mutant and japonica variety Wuyujing7 or indica variety 93-11. Leaves had a normal, green appearance in all $F_{1}$ plants. Among the $F_{2}$ population, the segregation ratio of normal green to albino was in accordance with 3:1 (Additional file 2: Table S3). These results indicate that the $t s c d 11$ phenotype is controlled by a single recessive nuclear gene.

For fine mapping of the TSCD11 locus, we generated a $\mathrm{F}_{2}$ mapping population from the cross between the tscd11 mutant and indica variety 93-11. Using $21 \mathrm{~F}_{2}$ mutant individuals, we mapped TSCD11 between STS markers B11-12 and B11-13 on chromosome 11 (Fig. 3a). To further fine map the TSCD11, we designed new insertion/deletion (INDEL) markers between B1112 and B11-13 based on sequence differences between 93 and 11 and Nipponbare. With $197 \mathrm{~F}_{2}$ mutant individuals, the TSCD11 locus was finally narrowed to a $103-\mathrm{kb}$ region between INDEL markers P2 and P3 (Fig. 3b). The region includes 17 predicted ORFs (http://rice.plantbiology.msu.edu/index.shtml; Fig. 3c). Sequencing of all annotated genes in target region found a single nucleotide mutation $(\mathrm{G} \rightarrow \mathrm{A})$ at $3036 \mathrm{bp}$ from the start codon ATG in LOC_Os11g39670, which resulted in an amino acid substitution of lysine for glutamic acid (Fig. 3d).

To verify that the single nucleotide mutation of TSCD11 is responsible for the tscd11 mutant phenotype, we constructed a complementation vector with a wildtype genomic fragment containing the entire coding

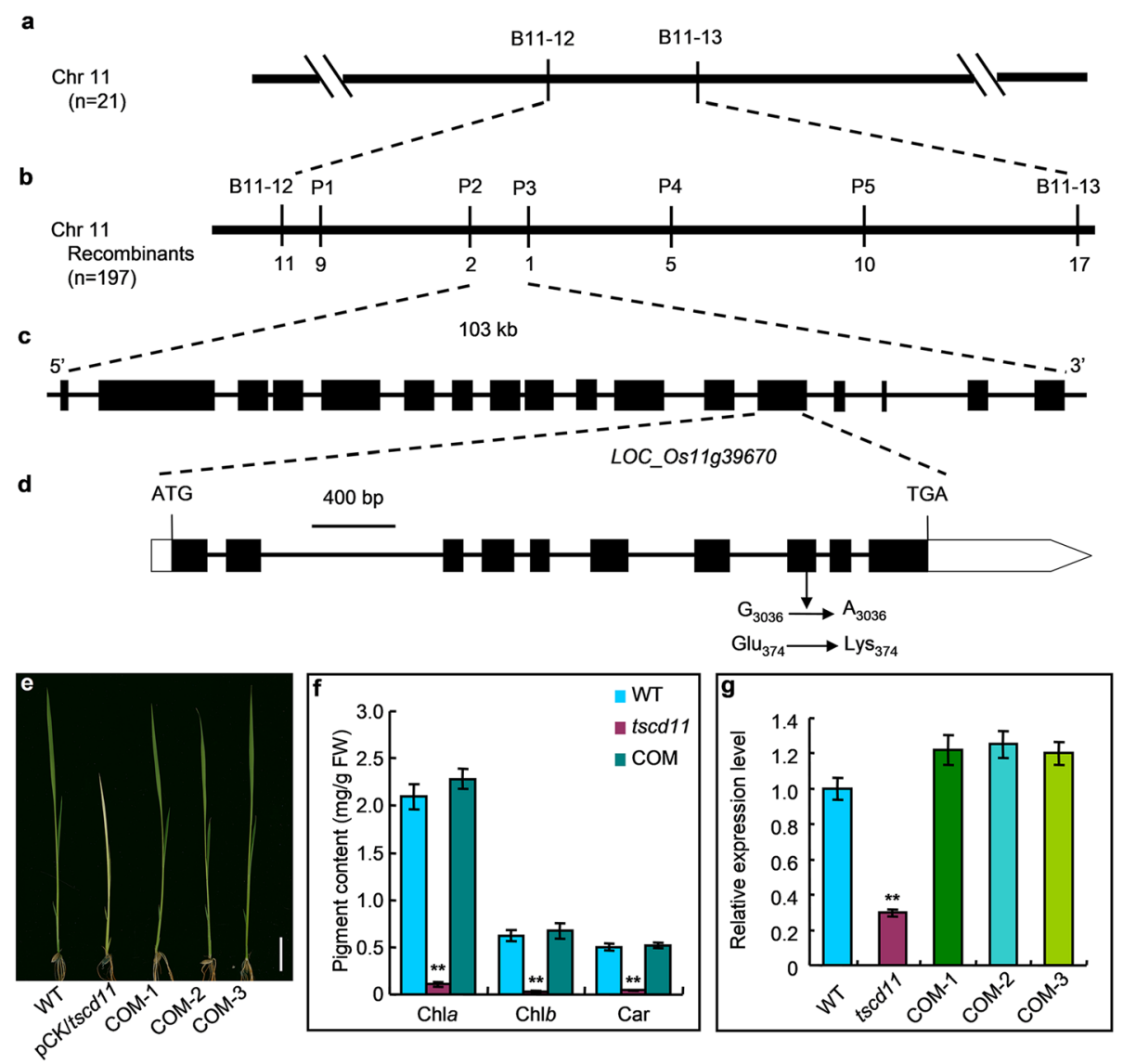

Fig. 3 Map-based cloning of TSCD11 and transgenic complementation of the tscd11 mutant. a, b The TSCD11 locus was initially mapped on chromosome 11. c, Fine mapping the TSCD11 locus. d, TSCD11 gene structure and mutation site of TSCD11. e, phenotypes of wild-type, tscd11 with pCMBIA1300 ( $\mathrm{pCK} / \mathrm{tscd} 11)$ and three independent $t s c d 11$ complementation plants $\left(\mathrm{COM}-1,2\right.$ and 3 ) at $35^{\circ} \mathrm{C}(\mathrm{bar}=2 \mathrm{~cm})$. f, pigment contents of wild-type, tscd11 and complementation plants $\mathbf{g}$. Relative transcript levels of TSCD11 in wild-type, tscd11 and complementation plants at the 3leaf stage at $35^{\circ} \mathrm{C}$. The rice Histone gene was used as an internal control. The transcript level of $\operatorname{TSCD} 11$ in the WT at $35^{\circ} \mathrm{C}$ was set to 1.0 . Data represent the mean $\pm \mathrm{SD}(\mathrm{n}=3) .{ }^{* *} p<0.01$ (Student's $t$-test) 
region of TSCD11, along with 1999 bp of upstream promoter sequence and $846 \mathrm{bp}$ of downstream sequence. The fragment was inserted into the binary vector pCAMBIA1300, and the construct pCAMBIA1300TSCD11 was introduced into the tscd11 mutant by Agrobacterium-mediated transformation. As expected, all 26 independent transgenic plants with pCAMBIA1300TSCD11 displayed WT phenotype under high temperature, whereas all 5 independent lines transformed with the empty vector maintained $t s c d 11$ mutant phenotype (Fig. 3e). Consistently, contents of $\mathrm{Chl}$ and Car, together with expression levels of TSCD11 in the wild-type plants and all complementation plants were significantly higher than those of $t s c d 11$ plants under high temperature (Fig. 3f, g). These results confirm that LOC_Os11g39670 is TSCD11.

\section{Sequence and Phylogenetic Analysis of TSCD11}

The TSCD11 gene is composed of ten exons and encodes a seryl-tRNA synthetase, a 509-amino acid protein with molecular mass of approximately $56 \mathrm{kD}$. BLASTP analysis showed that TSCD11 has a seryl-tRNA synthetase (SerRs) class II catalytic domain, involving the mutated amino acid in tscd11. BLASTP analysis also found that TSCD11 is highly conversed in plants including Brachypodium distachyon, Sorghum bicolor, Setaria italica, Triticum turgidum, Aegilops tauschii, Zea mays, Medicago truncatula, Cicer arietinum and Arachis ipaensis (Fig. 4a). Among these species, rice TSCD11 showed the highest homology with Sorghum bicolor (88\%). Phylogenetic analysis of TSCD11 was performed to investigate the evolutionary relationship among TSCD11 homologs. As shown in Fig. 4b, TSCD11 homologues can be divided into two clusters: monocots and dicotyledons, and OsTSCD11 belongs to monocots cluster.

\section{Expression of TSCD11 Is Affected by Temperature and TSCD11 Protein Is Localized to Chloroplasts}

In order to examine the expression pattern of TSCD11 in the WT, we used qRT-PCR to investigate the transcript levels of TSCD11 in roots, stems, leaves, sheaths and panicles. TSCD11 was expressed in all tissues with highest expression in leaves (Fig. 5a). To further verify the tissue-specific expression of TSCD11, the promoter of TSCD11 (1999 bp upstream of ATG) was amplified from wild-type genomic DNA and inserted into the binary vector pCAMBIA1305, and the construct pCAMBIA1305-TSCD11 was then introduced into the WT by Agrobacterium-mediated transformation. Consisting with $\mathrm{qRT}$-PCR, $\beta$-glucuronidase (GUS) staining showed the same results (Fig. $5 \mathrm{~b}$ ). To further investigate whether the mutation and temperature affect TSCD11 expression, we detected transcript levels of TSCD11 in 3-leaf stage seedlings of the WT and tscd11, and found that TSCD11 expression was significantly lower in the $t s c d 11$ mutant compared to the WT at $25^{\circ} \mathrm{C}$ and $35^{\circ} \mathrm{C}$, with even lower in $t s c d 11$ plants grown at $35^{\circ} \mathrm{C}$ (Fig. 5c). Specifically, the expression level of TSCD11 in the tscd11 mutant was decreased to $73.8 \%$ and $30.4 \%$ of the WT at $25^{\circ} \mathrm{C}$ and $35^{\circ} \mathrm{C}$, respectively. These results suggested that TSCD11 expression was inhibited in the tscd11 mutant and high temperature enhanced the inhibition.

The pTSCD11-GFP plasmid and the empty GFP plasmid were respectively introduced into rice protoplasts to examine subcellular localization of TSCD11. Confocal microscopy showed the TSCD11-GFP fusion protein localized to the chloroplast (Fig. 6).

\section{The Transcriptional Expression of Functionally Related Genes Are Affected in the tscd11 Mutant}

Given that TSCD11 protein is localized to chloroplasts, the expression levels of genes related to chloroplast development might be affected. We then determined expression levels of 16 representative genes associated with Chl biosynthesis, photosynthesis and chloroplast development. At $35^{\circ} \mathrm{C}$, expression levels of $\mathrm{Chl}$ biosynthesis genes encoding divinyl reductase $(D V R), \mathrm{Mg}$-chelatase $\mathrm{H}$ subunit $(C H L H)$, protochlorophyllide oxidoreductase A (OsPORA) and chlorophyll a oxygenase (CAO1) were significantly reduced in the tscd11 mutant compared to the WT (Fig. 7d), in accordance with the albino phenotype and decreased Chl content in tscd11 (Fig. 1g, j). The transcript levels of photosynthesis related genes Photosystem I Subunit A (PsaA), Photosystem II Subunit of $A$ (PsbA), Rice Chlorophyll $a / b$ Binding Protein (CAB2R), Rubisco Large Subunit (RbcL) were also significantly down-regulated in tscd11 compared with the WT (Fig. 7e). In comparison with the WT, expression levels of chloroplast development related genes Plastid RNA Polymerase (OsRpoTp), FtsZ, Thioredoxinz (TRXz), PfkBtype Carbohydrate Kinase Family Protein (FLN2), Chloroplast $50 S$ Ribosome Protein L21 (rpl21), Virescent1 (V1), Virescent2 (V2), 23 S ribosomal RNA (23SrRNA) decreased significantly in tscd11 (Fig. 7f). These results were consistent with the impaired chloroplast in the tscd11 mutant under high temperature (Fig. 2d, h). By contrast, expression levels of almost affected genes at $35^{\circ} \mathrm{C}$ in the $t s c d 11$ mutant had little difference with those of the WT at $25^{\circ} \mathrm{C}$ (Fig. $7 \mathrm{a}-\mathrm{C}$ ).

\section{Discussion}

\section{TSCD11 Is Essential for Chloroplast Development under} High Temperature

Chloroplasts are the main organelles for photosynthesis in plants, encoding only about 100 genes (Leister 2003). Thus, the expression of these chloroplast-related genes is essential for chloroplast development. With global 
a Bd XP_-003577370.1 $S 1 \mathrm{XP}^{-} 004979699.1$ Tt VAî2 29997. At XP_020170590. Me XP ${ }^{-} 003602834$. Ca XP 004501691.1 A1 XP_-016163653.1

Os XP_015615389.1 Bd XP
Sb XP 003577370.1

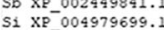

Tt VĀ 29997 .

At XP_020170590.

Zm MP ${ }^{2}-001292796.1$

Ca XP-004501691.

$\mathrm{Ai} \mathrm{XP}_{-} 016163653.1$

Os $\mathrm{XP}_{-} 015615389.1$ Bd XP_-003577370.

$S 4$ XP 004979699 .

Tt VA $\bar{I} 29997.1$

As $X \mathrm{PP} 020170590$

Zm NP 001292796.1

Mt XP-003602834.1

Ca XP-004501691.1

Ai XP_016163653.1

Os XP_015615389.1

Bd XP-003577370.

51 XP- 004979699.1

Tt VAI29997.1

At $\mathrm{XP}-020170590$. 1

2m NP 001292796.1

Ca XP-004501691.

A1 XP-016163653.

Os XP 015615389.1

$\mathrm{Sb} \mathrm{XP}_{-}-002449841.1$

Si $\mathrm{XP}^{-} 004979699$

Tt VAr29997.1

Zm NP_-001292796.

Me XP-003602834.

Ca XP_-004501691.

Os XP_015615389.1

Bd XP-003577370.1

Sb XP 002449841.1

Si X XP

At XP 020170590

$2 \mathrm{~m} \mathrm{NP}-001292796$.

Me XP.

A. $X P^{-016163653}$

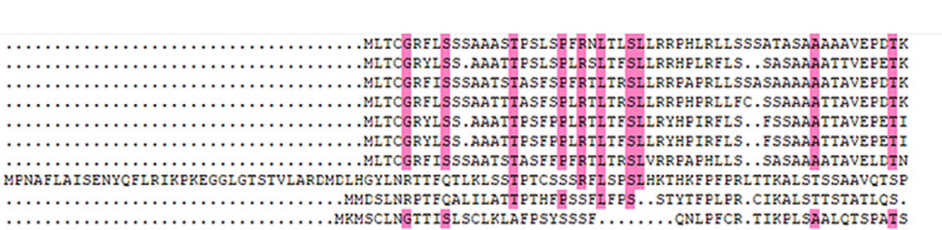

56
56
53
56
55
53
53
54
93
54
50
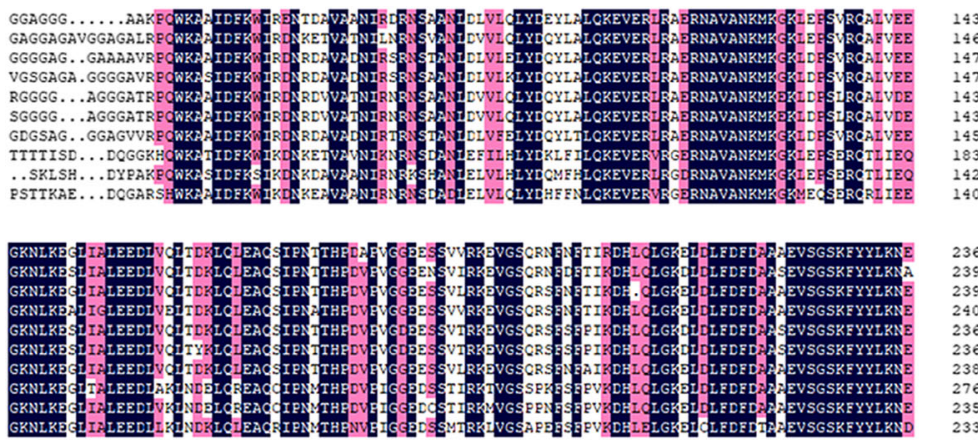

236
239
239
240
236
236
238
276
235
233

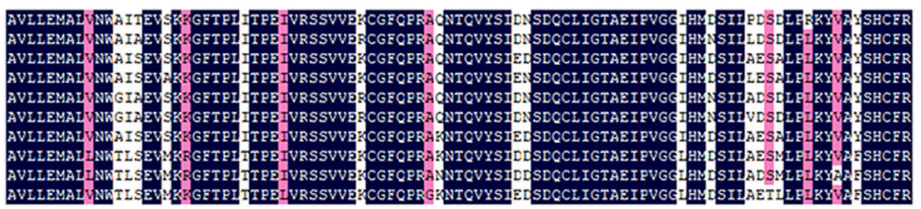

\section{332
332
333
332
329
331
369
328
326}

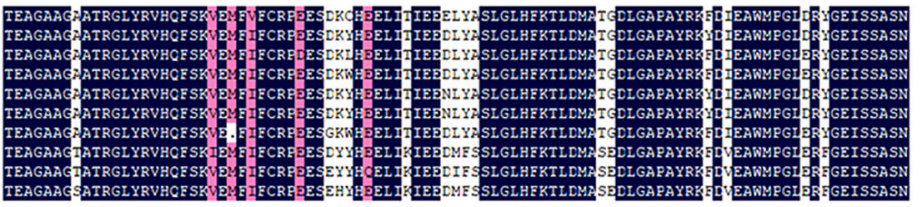

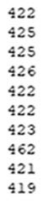

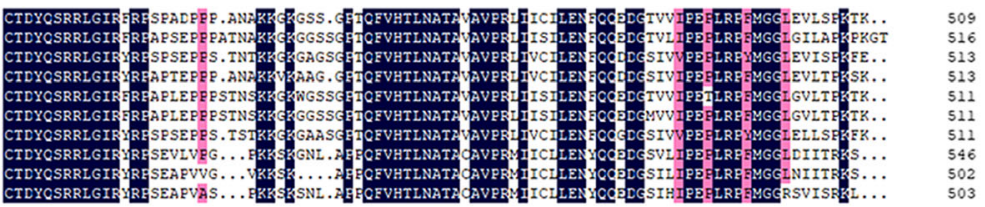

b

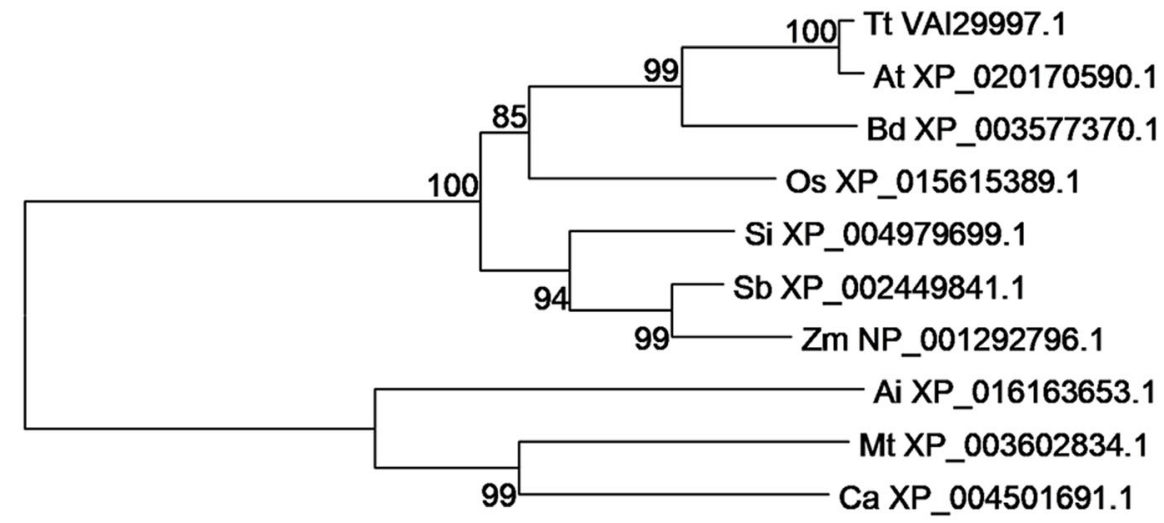

0.05

Fig. 4 (See legend on next page.) 
(See figure on previous page.)

Fig. 4 Phylogenic analysis of TSCD11. a, Amino acid sequence alignment of 10 types of TSCD11 homologs. Fully or partially conserved amino acids are shaded blue and pink, respectively. $\mathbf{b}$, Phylogenic tree of TSCD11 and its homologs. Protein sequences are Oryza sativa (Os XP_015615389.1), Brachypodium distachyon (Bd XP_003577370.1), Sorghum bicolor (Sb XP_002449841.1), Setaria italica (Si XP_004979699.1), Triticum turgidum (Tt VAl29997.1), Aegilops tauschii (At XP_020170590.1), Zea mays (Zm NP_001292796.1), Medicago truncatula (Mt XP_003602834.1), Cicer arietinum (Ca XP_004501691.1), Arachis ipaensis (Ai XP_016163653.1). The phylogenetic tree was constructed by MEGA version 6.0 software based on the neighbor-joining method (1000 replicates). Scale represents percentage substitution per site. Statistical support for the nodes is indicated

temperature rise overall, sudden high-temperature periods often occur in early seedling development in the field. It affects the expression of chloroplast-related genes, leading to chlorophyll deficiency/chloroplast defects, which ultimately could causes reduced yield of rice. Thus, the identification of mutants sensitive to high temperature and cloning of related gene are beneficial to elucidate the mechanism of chloroplast development at high temperature. At present, more than 80 chlorophyll deficient mutants have been identified in rice ( $\mathrm{Li}$ et al. 2013). Six high-temperature sensitive mutants have been identified, five of which displayed an chlorotic phenotype at high temperature (over $35^{\circ} \mathrm{C}$ ) (Zheng et al. 2016). The $c d e 1(t)$ mutant produced yellow green leaves at over $26^{\circ} \mathrm{C}$, while exhibited normal phenotype at lower temperatures $\left(23^{\circ} \mathrm{C}\right.$ and $20^{\circ} \mathrm{C}$ ) (Liu et al. 2007). These phenotypes most likely caused by mutation of the candidate gene OsGluRS. The tcm 5 mutant displayed albino phenotype at $32{ }^{\circ} \mathrm{C}$, but was normal at $20^{\circ} \mathrm{C}$ (Zheng et al. 2016). The hsa1 mutant showed albino phenotype at $32{ }^{\circ} \mathrm{C}$, while exhibited normal phenotype at $24{ }^{\circ} \mathrm{C}$ (Qiu et al. 2017). Similar to the $t c m 5$ mutant, the $t s c d 11 \mathrm{mu}-$ tant had albino leaves and even dead during the 4-5 leaf stage at $35^{\circ} \mathrm{C}$, while appeared normal at $25^{\circ} \mathrm{C}$. Furthermore, temperature shift experiments showed that the phenotype of $t s c d 11$ changed significantly in both $25^{\circ} \mathrm{C}$ shift to $35^{\circ} \mathrm{C}$ and $35^{\circ} \mathrm{C}$ shift to $25^{\circ} \mathrm{C}$, although the mutant's phenotype could not restore completely when shifted from $35^{\circ} \mathrm{C}$ to $25^{\circ} \mathrm{C}$ (Additional file 1: Fig. S1f, h).
Consistently, the pigment contents of tscd11 decreased significantly compared to the WT from $35^{\circ} \mathrm{C}$ to $25^{\circ} \mathrm{C}$, the pigment contents of $t s c d 11$ were significantly higher from $35^{\circ} \mathrm{C}$ to $25^{\circ} \mathrm{C}$ than those at $35^{\circ} \mathrm{C}$ (Additional file 1: Fig. S1g, h, k, l; Additional file 2: Table S1). Similar phenomena were also observed in thermo-sensitive chlorophyll-deficient mutant 11 (tcd11) (Wang et al. 2017). These high-temperature sensitive mutants displayed different phenotypes at different temperatures, which revealed different temperature sensitive mechanisms for chloroplast development in rice. Additionally, the chloroplast of tscd11 developed abnormally at high temperature and the transcripts of genes related to chloroplast development were also decreased in tscd11 at $35^{\circ} \mathrm{C}$ compared with WT (Fig. $7 \mathrm{~d}$-f). In contrast to high temperature, all transcripts of the affected genes at $35^{\circ} \mathrm{C}$ in the $\operatorname{tsc} 111$ at least partially restored to the WT level under low temperature $\left(25^{\circ} \mathrm{C}\right.$, Fig. $\left.7 \mathrm{a}-\mathrm{c}\right)$. These results can explain the difference in chloroplast development and leaf color between $25^{\circ} \mathrm{C}$ and $35^{\circ} \mathrm{C}$. Moreover, similar to the hsa1 mutant, the transcript levels of TSCD11 all significantly reduced in tscd11 compared with the WT at $25^{\circ} \mathrm{C}$ and $35^{\circ} \mathrm{C}$, with even lower in tscd11 plants grown at $35^{\circ} \mathrm{C}$. The results indicate that TSCD11 expression is inhibited in the tscd11 mutant and the inhibition enhanced by high temperature. In addition, the lethality of the tscd11 mutant may be due to prevention of chloroplast development at high temperature (Fig. 2d, h). Similar to TCM5 and HSA1,
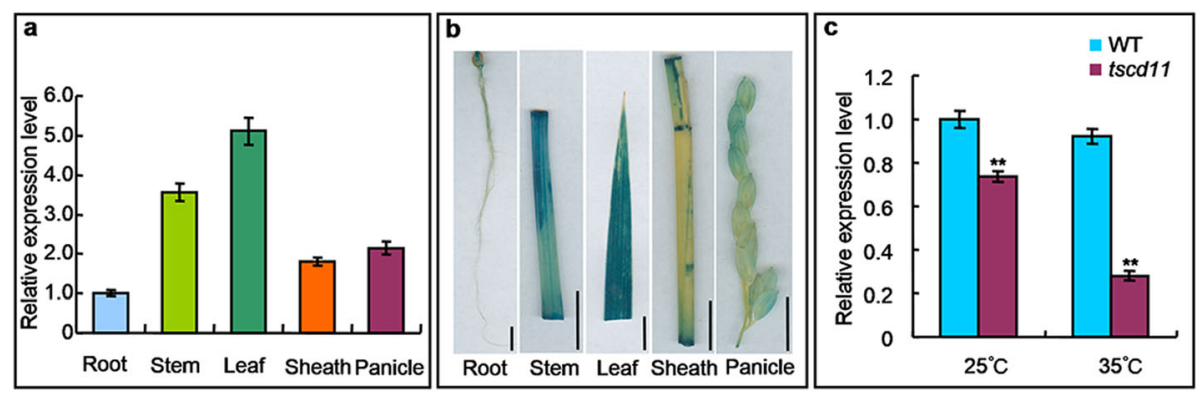

Fig. 5 Expression pattern of TSCD11. a, qRT-PCR analysis of TSCD11 gene in various tissues of wild-type plants. Data represent the mean \pm SD $(n=$ 3). b. GUS staining of root, stem, leaf, sheath and panicle in the TSCD11 promoter-GUS transgenic plants (bars $=1 \mathrm{~cm}$ ). $\mathbf{c}$, Relative transcript levels of TSCD11 in the WT and tscd11 at the 3-leaf stage grown at $25^{\circ} \mathrm{C}$ and $35^{\circ} \mathrm{C}$, respectively. The rice Histone gene was used as an internal control. The expression level of $T S C D 11$ in the $W T$ at $25^{\circ} \mathrm{C}$ was set to 1.0. Data represent mean $\pm S D(n=3) .{ }^{* *} p<0.01$ (Student's t-test) 

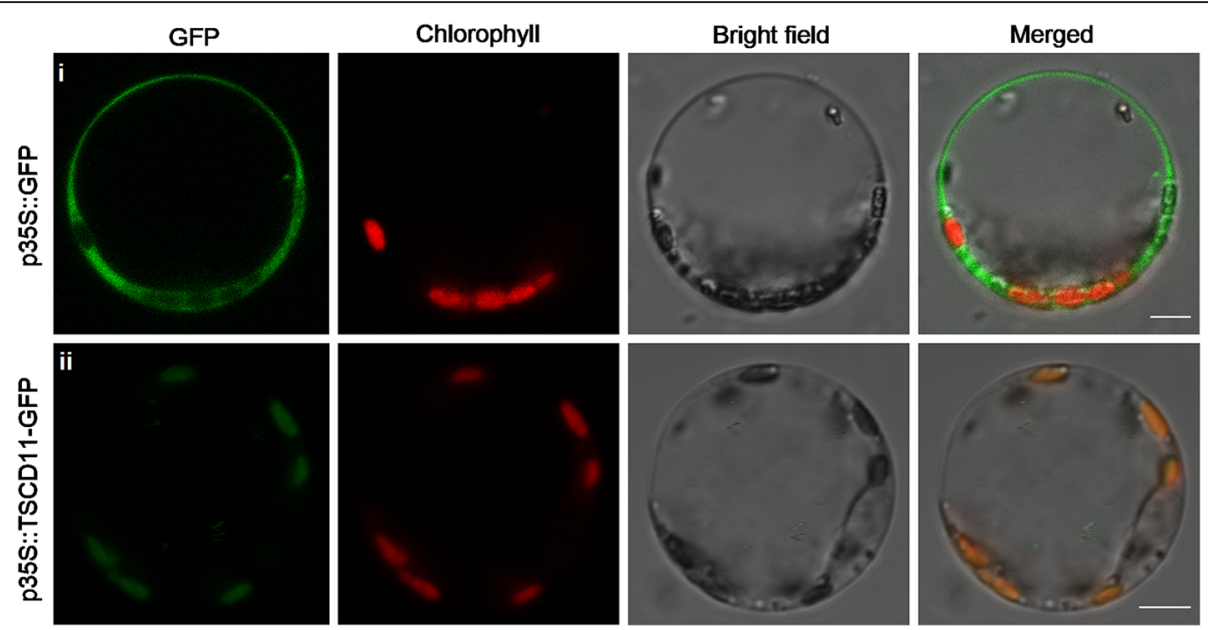

Fig. 6 Subcellular localization of the TSCD11-GFP protein in rice protoplasts. i. Empty GFP as a control. ii. p35S::TSCD11-GFP fusion localized to chloroplast (bar $=5 \mu \mathrm{m})$

TSCD11 protein is also localized to chloroplasts, confirming that the TSCD11 gene is required for chloroplast development at high temperature.

The TSCD11 gene encodes a seryl-tRNA synthetase, an essential enzyme for protein synthesis. Given that TSCD11 protein is localized to chloroplasts, we then determined expression levels of 9 chloroplast-encoded genes which are essential for chloroplast development. As shown in Fig. S5a, the expression levels of 7 chloroplast-encoded genes showed no significant difference between the WT and $t s c d 11$ at $25^{\circ} \mathrm{C}$. By contrast, the expression levels of all 9 chloroplast-encoded genes decreased significantly in tscd 11 at $35^{\circ} \mathrm{C}$ (Fig. $\mathrm{S} 5 \mathrm{~b})$. And chloroplasts were observed impaired without stacked grana or stromal thylakoids in tscd11 plants compared with the WT at $35^{\circ} \mathrm{C}$ (Fig. $2 \mathrm{~d}, \mathrm{~h}$ ). These results suggested that TSCD11 was essential in the process of chloroplast development under high temperature. According to previous studies, it was found that chloroplast development is a complex process, and the process from

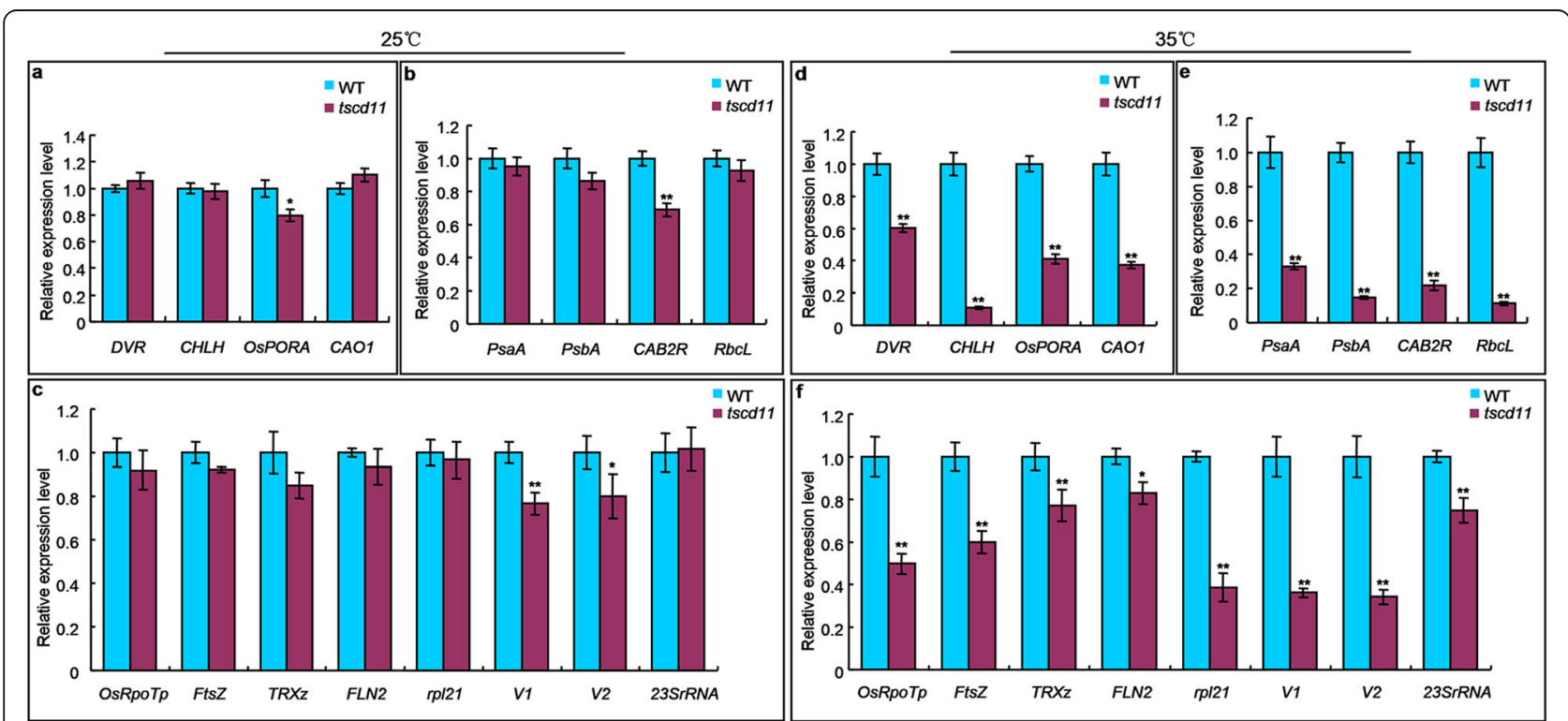

Fig. 7 Transcriptional expression of genes related to Chl biosynthesis, photosynthesis and chloroplast development. a-c Expression of genes associated with $\mathrm{Chl}$ biosynthesis (a), photosynthesis (b) and chloroplast development (c) in WT and tscd11 mutant at $25^{\circ} \mathrm{C}$. d-f Expression of genes associated with $\mathrm{Chl}$ biosynthesis (d), photosynthesis (e) and chloroplast development (f) in WT and tscd11 mutant at $35^{\circ} \mathrm{C}$. The rice Histone gene was used as an internal control. The expression level of each tested gene in WT was set to 1.0. Data represent mean $\pm \mathrm{SD}(\mathrm{n}=3) .{ }^{*} p<0.05$, ** $p<0.01$ (Student's $t$-test) 
protoplast to mature chloroplast could be divided into three important steps. The third step involves high expression of genes related to photosynthesis (Jarvis and López-Juez 2013). PsaA, PsbA, CAB2R and RbcL are typical genes involved in the third step. Because their expression were all declined significantly at $35^{\circ} \mathrm{C}$ in $t s c d 11$ compared to the WT (Fig. 7e), the mutation in TSCD11 may affect the expression of photosynthesis related genes under high temperature.

\section{ROS Induces the Expression of Genes Related to ROS Detoxification}

As the Chloroplasts impaired, the plants are often weakness in growth. And the weakness plants are sensitive to ROS, especially under stress situation (Chen et al. 2018). The common stress situations include high temperature or high light. ROS acted as a signal to induce change in genes expression (Baxter et al. 2014; Triantaphylidès 2008). To verify it in the tscd11 mutant, we measured contents of ROS-related substances. At $25^{\circ} \mathrm{C}$, contents of $\mathrm{H}_{2} \mathrm{O}_{2}$ and $\mathrm{MDA}$, and CAT activity had no difference between the WT and the tscd11 mutant (Additional file 1: Fig. S3c-e). However, at $35^{\circ} \mathrm{C}$, contents of $\mathrm{H}_{2} \mathrm{O}_{2}$ and MDA were notably increased in tscd11, and the activity of CAT was significantly decreased compared to the WT (Additional file 1: Fig. S3h-j). Interestingly, the expression of genes related to ROS detoxification, such as AOX1a, AOX1b, APX1, CATB, SODA1 and SODB were significantly induced in the $t s c d 11$ mutant. Although the expression levels of all antioxidant genes were dramatically increased at $35^{\circ} \mathrm{C}$ (Additional file 1 : Fig. S31), excess ROS still accumulated in tscd11 at high temperature (Additional file 1:Fig. S3h-j). Similar phenomena were also observed in the $A B A$ overlysensitive5 (abo5), local lesions 1 (ls1), and slow growth 1 (slg1) mutants (Liu et al. 2010; Qiu et al. 2019; Yuan and Liu 2012). Therefore, it is possible that increased expression of those genes may not be sufficient for reducing ROS to normal levels in the tscd11 mutant at high temperature.

\section{Conclusion}

The TSCD11 encodes a chloroplast-targeted seryltRNA synthetase which is essential for early chloroplast development, especially at high temperature. These results provide basis for further study on the molecular mechanism of chloroplast development under high temperature.

\section{Methods}

Plant Materials and Growth Conditions

In this study, tscd11 (temperature -sensitive chlorophylldeficient mutant 11) was obtained from japonica variety
Wuyujing7 (WT) by ethyl methane sulfonate (EMS). An $\mathrm{F}_{2}$ segregating population was derived from a cross between the tscd11 and indica cultivar 93-11 for fine mapping TSCD11 locus. All rice plants were planted in the paddy field during the normal season in two different successive months (May and June) at Hangzhou. In the $\mathrm{F}_{2}$ population, the plants with albino phenotype were selected for genetic mapping. For temperature treatment experiments, the WT and tscd11 seeds were grown in growth chambers $(12 \mathrm{~h}$ of light and $12 \mathrm{~h}$ of dark; light intensity $200 \mu \mathrm{mol} \mathrm{m}^{-2} \mathrm{~s}^{-1}$ ) at different temperatures $\left(25^{\circ} \mathrm{C}, 30^{\circ} \mathrm{C}\right.$ and $\left.35^{\circ} \mathrm{C}\right)$. For temperature transition experiments of $25^{\circ} \mathrm{C}$ shift to $35^{\circ} \mathrm{C}$ and $35^{\circ} \mathrm{C}$ shift to $25^{\circ} \mathrm{C}$, the WT and tscd11 seeds were grown in growth chambers $(12 \mathrm{~h}$ of light and $12 \mathrm{~h}$ of dark; light intensity $200 \mu \mathrm{mol} \mathrm{m}{ }^{-2} \mathrm{~s}^{-1}$ ) at the temperature of $25^{\circ} \mathrm{C}$ or $35^{\circ} \mathrm{C}$ till the 2-leaf stage, and then grown in growth chambers (12 h of light and $12 \mathrm{~h}$ of dark; light intensity $200 \mu \mathrm{mol}$ $\mathrm{m}^{-2} \mathrm{~s}^{-1}$ ) at the temperature of $35^{\circ} \mathrm{C}$ or $25^{\circ} \mathrm{C}$ from the 2-leaf stage to the 3-leaf stage. The wild-type and $t s c d 11$ seeds were grown hydroponically in nutrient solution in growth chambers as previously described (Ueno et al. 2009).

\section{Pigment Content and Agronomic Traits Measurent}

Fresh leaves $(0.05 \mathrm{~g})$ were sampled from the WT and $t s c d 11$ plants at the 3-leaf stage grown in growth chambers and in the paddy field in different growth periods, and cut into small pieces, respectively. These leaves were completely immersed in $5 \mathrm{ml} 95 \%$ ethanol with three biological repeats and keep them in dark at $26^{\circ} \mathrm{C}$ until $24 \mathrm{~h}$ later. The contents of chlorophyll $a(\mathrm{Chl} a)$, chlorophyll $b(\mathrm{Chl} b)$, and carotenoids (Car) were determined according to the methods described by Arnon (1949) and Wellburn (1994) Taking $1 \mathrm{ml}$ samples solution were measured at $663 \mathrm{~nm}, 645 \mathrm{~nm}$ and $470 \mathrm{~nm}$, using ultraviolet spectrophotometer (DU800, Beckman, USA). Wildtype and tscd11 mutant plants were grown in experimental rice fields of Hangzhou. And we surveyed some agronomic traits of the wild-type and $t s c d 11$ plants at maturity (Additional file 2: Table S2).

\section{Transmission Electron Microscopy Analysis}

Fresh leaves of the wild-type and $t s c d 11$ plants at the 3leaf stage grown at $25^{\circ} \mathrm{C}$ or $35^{\circ} \mathrm{C}$ in growth chambers were collected and cut into small pieces. Then samples were fixed in $2.5 \%$ glutaraldehyde in phosphate buffer $(\mathrm{pH}=7.4)$ at $4{ }^{\circ} \mathrm{C}$ for $4 \mathrm{~h}$ after vacuum and then in $1 \%$ $(\mathrm{w} / \mathrm{v}) \mathrm{OsO}_{4}$. TEM assays were done according to the method described by Gothandam et al. (2005). The samples were examined with a Hitachi H-7650 transmission electron microscope. 
Histochemical Staining, Determination of ROS-Related Physiological Index and TUNEL Assay

Superoxide anion was detected by NBT, DAB staining according to the method described by Thordal-Christensen et al. (2010). $\mathrm{H}_{2} \mathrm{O}_{2}$, MDA contents and CAT activity of WT and tscd11 were measured as described by Moradi and Ismail (2007). The TUNEL assay was performed with Fluorescein in Situ Cell Death Detection Kit (Roche), according to the method of Huang et al. (2007). The leaves of WT and tscd11 were fixed with FAA fixative and embedded in paraffin. The sections were microscopically examined to select slides and dewaxed by gradient alcohol. The slides were immersed in $4 \%$ methanol-free formaldehyde in PBS, and tissue sections were permeabilized with proteinase K. Equilibration Buffer was then added and covered with plastic coverslip. After incubation in another buffer containing Equlibration Buffer, Nucleotide Mix and rTdT Enzyme at $37^{\circ} \mathrm{C}$ in the dark for $1 \mathrm{~h}$, the slides were dipped in $2 \times$ SSC without plastic coverslip. Cells were then stained with PI and the localized green fluorescence $(520 \mathrm{~nm})$ of apoptotic cells (fluorescein-12-dUTP) in a red fluorescence $(620 \mathrm{~nm})$ background (PI) were detected by confocal fluorescence scanning microscope (LSM700, Carl Zeiss, Inc., USA). Histochemical staining, determination of ROS-related physiological index and TUNEL assay were performed on the top leaves from the wild-type and tscd11 plants at the 3-leaf stage, which were grown at $25^{\circ} \mathrm{C}$ or $35^{\circ} \mathrm{C}$ in growth chambers.

\section{Genetic Analysis and Map-Based Cloning of TSCD11}

For the genetic analysis, crosses were performed between the tscd11 mutant and Wuyujing7 (Japonica variety) or 9311 cultivar (indica variety), respectively. For fine mapping of TSCD11 locus, 197 mutant individuals were selected from $\mathrm{F}_{2}$ population to map the TSCD11 locus. The genomic DNA was extracted from $F_{2}$ plants, according the CTAB method (Murray and Thompson 1980) SSR markers were obtained from the Gramene database (http://www. gramene.org). In order to narrow the target interval, new polymorphic markers were designed, which were based on the sequence differences between the japonica rice cultivar Nipponbare and the indica cultivar 93-11.These markers are listed in Additional file 2: Table S4.

\section{Vector Construction and Transformation}

For complementation of the tscd11 mutant, a 6449-bp genomic DNA fragment containing entire TSCD11 coding region, 1999-bp upstream sequence and 846-bp downstream sequence was amplified by PCR using the primers TSCD11-COM F/R. PCR products were digested with Kpn I and BamH I. The target fragment was purified and cloned into the binary vector pCAMBIA1300. The pCAMBIA1300-TSCD11 vector and control vector (pCAMBIA1300, CK) were introduced into the tscd11 mutant by Agrobacterium-mediated. The 1999-bp sequence of TSCD11 promoter was amplified by PCR using the primers TSCD11-GUS F/R. PCR products were digested with Hind III and Nco I. The fragment was cloned into the binary vector pCAMBIA1305. Primers used for vector construction are listed in Additional file 2: Table S5.

\section{Phylogenetic Analysis}

The full-length sequence of TSCD11 protein was obtained using Gramene (http://www.gramene.org). The blast analysis was performed to find homologues of TSCD11 on the NCBI website (NCBI, http//www.ncbi.nlm.nih.gov). Multiple sequences were aligned and a phylogenetic tree was constructed by MEGA version 6.0 software based on the neighbor-joining method (1000 replicates).

\section{Subcellular Location of TSCD11 in Rice Protoplast}

To investigate the subcellular localization of TSCD11, the TSCD11 full-length CDNA without termination codon was cloned into the GFP vector pCA1301-35SS65T-GFP (Ren et al. 2017). We amplified the fulllength TSCD11 coding sequence without the termination codon with primers TSCD11-GFP F/R (Additional file 2: Table S5). According the previous protocols, the construct (p35S:: TSCD11-GFP) and control vector were transformed into rice chloroplast (Yu et al. 2014). Fluorescence signals were observed with confocal fluorescence scanning microscope (LSM700, Carl Zeiss, Inc., USA).

\section{RNA Extraction and Quantitative Real Time PCR (qRT-PCR) Analysis}

To understand the expression pattern of TSCD11, Total RNA was extracted from roots, stems, leaves, sheaths and panicles of wild-type plants grown in the paddy field. For transcriptional expression analysis of TSCD11 and 36 genes (WRKY72, Osh36, SGR, WRKY24, WRKY70, AOX1a, AOX1b, APX1, CATB, SODA1, SODB, DVR, CHLH, OsPORA, CAO1, psaA, psbA, CAB2R, RbcL, OsRpoTp, FtsZ, TRXz, FLN2, rpl21, V1, V2, 23SrRNA, AtpB, AtpE, 16SrRNA, rpl23, rps7, rps10, rps18, rps19, rps20) associated with senescence, ROSresponsive, detoxification, Chl biosynthesis, photosynthesis and chloroplast development, total RNA was obtained from the fresh leaves of the WT and $t s c d 11$ plants at the 3-leaf stage grown at $25^{\circ} \mathrm{C}$ or $35^{\circ} \mathrm{C}$ in growth chambers.

Total RNA was extracted using the AxyPrep total RNA Miniprep Kit (Axygen) according to the manufacturer's instructions. The extracted RNA was reversetranscribed using the Rever TraAce quantitative PCR RT Master Mix Kit with gDNA remover (Toyobo) according to the manufacturer's instructions. qRT-PCR experiment was performed on the ABI PRISM 7900HT Sequence 
Detector (Applied Biosystems). All primers sequences for qRT-PCR are listed in Additional file 2: Table S6. The rice Histone gene was used as an internal control. The expressed data were the means of three biological replicates. A Student's $t$-test was performed for statistical analysis.

\section{Supplementary information}

Supplementary information accompanies this paper at https://doi.org/10. 1186/s12284-020-00411-6.

Additional file 1 Fig. S1 Comparison of phenotypes and pigment contents between the wild-type and tscd11 plants. a-d Phenotypes of the WT and $t s c d 11$ at the 2-leaf stage grown at continuous $25^{\circ} \mathrm{C}(\mathbf{a}, \mathbf{b})$ and $35^{\circ} \mathrm{C}(\mathbf{c}, \mathbf{d})$, respectively. e-h Phenotypes of the WT and tscd11 at the 3-leaf stage grown at continuous $25^{\circ} \mathrm{C}$, shift $25^{\circ} \mathrm{C}$ to $35^{\circ} \mathrm{C}$, continuous $35^{\circ} \mathrm{C}$, shift $35^{\circ} \mathrm{C}$ to $25^{\circ} \mathrm{C}$, respectively. Bar $=2 \mathrm{~cm}$. i-I Pigment contents of the new third leaf of the wild-type and $t s c d 11$ plants grown at continuous $25^{\circ} \mathrm{C}$, shift $25^{\circ} \mathrm{C}$ to $35^{\circ} \mathrm{C}$, continuous $35^{\circ} \mathrm{C}$, shift $35^{\circ} \mathrm{C}$ to $25^{\circ} \mathrm{C}$ at the 3-leaf stage. Data represent mean $\pm \mathrm{SD}(n=3) .{ }^{*} p<0.05$, ** $p<0.01$ (Student's $t$-test). Fig. S2 Phenotypes and pigment contents comparison between wild-type and tscd11 plants. a, d Phenotypes of the $\mathrm{WT}$ and $t s \mathrm{~cd} 11$ at the tillering $(\mathrm{bar}=12 \mathrm{~cm})$, and heading stage ( $\mathrm{bar}=10$ $\mathrm{cm}$ ), respectively, in the paddy field. $\mathbf{b}$, e Close-up image of wild-type leaf and $t s c d 11$ leaf at the tillering, and heading stage $(\mathrm{bar}=5 \mathrm{~cm})$, respect-

ively. c, f Pigment contents of WT and tscd11 at the tillering, and heading stage, respectively. Data represent mean $\pm \mathrm{SD}(\mathrm{n}=3)$. ${ }^{*} p<0.05,{ }^{* *} p<$ 0.01 (Student's $t$-test). Fig. $\mathbf{S 3}$ ROS accumulation and genomic DNA fragmentation in the tscd11 mutant. $\mathbf{a}, \mathbf{b}, \mathbf{f}, \mathbf{g} \mathrm{DAB}(\mathbf{a}, \mathbf{f})$ and NBT $(\mathbf{b}, \mathbf{g})$ stain ing of leaves from wild-type and $\operatorname{tscd} 11$ plants at $25^{\circ} \mathrm{C}(\mathbf{a}, \mathbf{b})$ and $35^{\circ} \mathrm{C}(\mathbf{f}$, g), respectively $(\mathrm{bar}=1 \mathrm{~cm}) . \mathbf{c}-\mathbf{e}, \mathbf{h}-\mathbf{j}$ Statistic analysis of $\mathrm{H}_{2} \mathrm{O}_{2}$ content (c, h), MDA content $(\mathbf{d}, \mathbf{i})$, CAT activity $(\mathbf{e}, \mathbf{j})$ at $25^{\circ} \mathrm{C}(\mathbf{c}-\mathbf{e})$ and $35^{\circ} \mathrm{C}(\mathbf{h}-\mathbf{j})$, respectively. k, I Relative expression levels of senescence, ROS-responsive and ROS detoxification related genes in wild-type and tscd11 plants at $25^{\circ} \mathrm{C}(\mathbf{k})$ and $35^{\circ} \mathrm{C}(\mathbf{I})$ The rice Histone gene was used as an internal control. The expression level of each tested genes in WT was set to 1.0. Data represent mean $\pm S D(n=3)$. * $p<0.05,{ }^{* *} p<0.01$ (Student's $t$-test). Fig. S4 TUNEL assay of wild-type and tscd11 leaves at $25^{\circ} \mathrm{C}$ and $35^{\circ} \mathrm{C}$. Red signal is PI staining, green color represents positive result of apoptotic cells (bar $=50 \mu \mathrm{m}$ ). $\mathbf{a}, \mathbf{b}$ leaves from wild-type and $t s c d 11$ plants at $25^{\circ} \mathrm{C}$. c, d leaves from wild-type and tscd 11 plants at $35^{\circ} \mathrm{C}$. Fig. S5 Transcriptional expression of chloroplast-encoded genes. a, Expression of chloroplast-encoded genes in the WT and tscd 11 mutant at $25^{\circ} \mathrm{C}$. b, Expression of chloroplast-encoded genes in the WT and tscd11 mutant at $35^{\circ} \mathrm{C}$. The rice Histone gene was used as an internal control. The expression level of each tested gene in the WT was set to 1.0. Data represent mean $\pm \mathrm{SD}(\mathrm{n}=3) .{ }^{*} p<0.05,{ }^{* *} p<0.01$ (Student's $t$-test).

Additional file $\mathbf{2}$ Table $\mathbf{S 1}$ Pigment contents of the WT and the tscd11 mutant Table S2 Agronomic characters of the WT and the tscd11 mutant. Table S3 Genetic analysis of tscd11. Table S4 Primers used for fine mapping. Table S5 Primers used for vector construction. Table $\mathbf{5 6}$ Primers used for qRT-PCR.

\section{Abbreviations}

AARS: Aminoacyl-tRNA synthetases; AOX1a, AOX1b: Alternative Oxidase: APX1: Ascorbate Peroxidase; AtpB: ATP synthase F1 beta subunit 2; CAB2R: Rice Chlorophyll a/b Binding Protein; CAO1: Chlorophyll a Oxygenase; Car: Carotenoid; CAT: Catalase; CATB: Catalase; Chl: Chlorophyll; Chl a: Chlorophyll $a$; Chl b: Chlorophyll b; CHLH: Mg-chelatase H subunit; DAB: 3, 3'-diaminobenzidine; DVR: Divinyl Reductase; FLN2: PfkB-type Carbohydrate Kinase Family Protein; $\mathrm{H}_{2} \mathrm{O}_{2}$ : Hydrogen peroxide; MDA: Malondialdehyde; NBT: Nitro blue tetrazolium; $\mathrm{O}_{2}^{-}$: superoxide anions;

OsPORA: Protochlorophyllide Oxidoreductase A; OsRpoTp: Plastid RNA Polymerase; PI: Propidium iodide; PsaA: Photosystem I Subunit A; PsbA: Photosystem II Subunit of A; qRT-PCR: quantitative real time PCR; RbcL: Rubisco Large Subunit; ROS: Reactive oxygen species; rpl21: Chloroplast $50 S$ Ribosome Protein L21; rpl23: Chloroplast $50 S$ Ribosome Protein L23;
SGR: Stay Green Rice; SODA1, SODB: Superoxide Dismutase; 23SrRNA: 23 S ribosomal RNA; TEM: Transmission electron microscopy; TRXz: Thioredoxinz; TUNEL: terminal deoxynucleotidyl transferase-mediated dUTP nick-end labeling; V1: Virescent1; V2: Virescent2; WRKY72, WRKY24, WRKY70: WRKY transcription factor; WT: Wild type

\section{Acknowledgements}

Not applicable.

\section{Authors' Contributions}

$Q Q, Z Y G, L B G, D L Z$ and GN F designed the experiments; GN F, SL Y, BP R, $C L L, A P Z, H Z J, S L D, B T, Y Z, N J, G J D$ and $Q Z$ performed the experiments; GN F, SL Y, ZY G and GH Z analyzed the data; GN F wrote the manuscript. $Z Y G, L Z$ and $Q Q$ revised the manuscript. All authors read and approved the manuscript.

\section{Funding}

This research was supported by the National Natural Science Foundation of China (Grant No. 31601284), State Key Laboratory of Rice Biology Research Project (2017ZZKT10103) and Projects of International Cooperation and Exchanges NSFC (31861143006).

\section{Availability of Data and Materials}

All relevant data are provided as figures or tables within the paper.

\section{Ethics Approval and Consent to Participate}

There are no ethics issues associated with this article.

\section{Consent for Publication}

All co-authors involved in the paper consent to publish this article in Rice.

\section{Competing Interests}

The authors declare that they have no competing interests.

Received: 4 December 2019 Accepted: 8 July 2020

Published online: 17 July 2020

\section{References}

Allakhverdiev SI, Kreslavski VD, Klimov W, Los DA, Carpentier R, Mohanty P (2008) Heat stress: an overview of molecular responses in photosynthesis. Photosynth Res 98:541-550

Arnon DI (1949) Copper enzymes in isolated chloroplasts. Polyphenoloxidase in Beta vulgaris. Plant Physiol 24:1-15

Banerjee R, Reynolds NM, Yadavalli SS, Rice C, Roy H, Banerjee P (2011) Mitochondrial aminoacyl-tRNA synthetase single-nucleotide polymorphisms that lead to defects in refolding but not aminoacylation. J Mol Biol 410:280293

Battisti DS, Naylor RL (2009) Historical warnings of future food insecurity with unprecedented seasonal heat. Science 323:240-244

Baxter A, Mittler R, Suzuki N (2014) ROS as key players in plant stress signalling. J Exp Bot 65:1229-1240

Bita CE, Gerats T (2013) Plant tolerance to high temperature in a changing environment: scientific fundamentals and production of heat stress-tolerant crops. Front Plant Sci 4:273

Bohra-Mishra P, Oppenheimer M, Hsiang SM (2014) Nonlinear permanent migration response to climatic variations but minimal response to disasters. Proc Natl Acad Sci U S A 111:9780-9785

Chen G, Wu C, He L, Qiu Z, Zhang S, Zhang Y, Guo L, Zeng D, Hu J, Ren D, Qian Q, Zhu L (2018) Knocking out the gene RLS1 induces hypersensitivity to oxidative stress and premature leaf senescence in rice. Int J Mol Sci 19:2853

Chen YE, Zhang CM, Su YQ, Ma J, Zhang ZW, Yuan M, Zhang HY, Yuan S (2017) Responses of photosystem II and antioxidative systems to high light and high temperature co-stress in wheat. Environ Exp Bot 135:45-55

Delannoy E, Le RM, Faivrenitschke E, Estavillo GM, Bergdoll M, Taylor NL, Pogson BJ, lan S, Imbault P, Gualbertoa JM (2009) Arabidopsis tRNA adenosine deaminase arginine edits the wobble nucleotide of chloroplast tRNAArg (ACG) and is essential for efficient chloroplast translation. Plant Cell 21:20582071

Gothandam KM, Kim ES, Cho H, Chung YY (2005) OsPPR1, a pentatricopeptide repeat protein of rice is essential for the chloroplast biogenesis. Plant Mol Biol 58:421-433 
Guo M, Yang XL, Schimmel P (2010) New functions of aminoacyl-tRNA synthetases beyond translation. Nat Rev Mol Cell Biol 11:668-674

Huang L, Sun Q, Qin F, Li C, Zhao Y, Zhou DX (2007) Down-regulation of a silent information regulator2-related histone deacetylase gene, OsSRT1, induces DNA fragmentation and cell death in rice. Plant Physiol 144:1508-1519

Jacob P, Hirt H, Bendahmane A (2017) The heat-shock protein/chaperone network and multiple stress resistance. Plant Biotechnol J 15:405-414

Jarvis P, López-Juez E (2013) Biogenesis and homeostasis of chloroplasts and other plastids. Nat Rev Mol Cell Biol 14:787-802

Jensen PE, Leister D (2014) Chloroplast evolution, structure and functions. F1000 Prime Rep 6:40

Jung KH, Hur J, Ryu CH, Choi Y, Chung YY, Miyao A, Hirochika H, An G (2003) Characterization of a Rice chlorophyll-deficient mutant using the T-DNA gene-trap system. Plant Cell Physiol 44:463-472

Kim YK, Lee JY, Cho HS, Lee SS, Ha HJ, Kim S, Choi D, Pai HS (2005) Inactivation of organellar glutamyl- and seryl-tRNA synthetases leads to developmental arrest of chloroplasts and mitochondria in higher plants. J Biol Chem 280: 37098-37106

Kumar SV, Wigge PA (2010) H2A. Z-containing nucleosomes mediate the thermosensory response in Arabidopsis. Cell 140:136-147

Kusumi K, Sakata C, Nakamura T, Kawasaki S, Yoshimura A, Iba K (2011) A plastid protein NUS1 is essential for build-up the genetic system for early chloroplast development under cold stress conditions. Plant J 68:1039-1050

Lee S, Kim JH, Yoo ES, Lee CH, An G (2005) Different regulation of chlorophyll a oxygenase genes in rice. Plant Mol Biol 57:805-818

Leister D (2003) Chloroplast research in the genomic age. Trends Genet 19:47-56

Li J, Wang Y, Chai J, Wang L, Wang C, Long W, Wang D, Wang Y, Zheng M, Cheng P, Niu M, Wan J (2013) Green-revertible Chlorina 1 ( $\operatorname{grc} 1$ ), is required for the biosynthesis of chlorophyll and the early development of chloroplasts in rice. J Plant Bio 56:326-335

Liu W, Fu Y, Hu G, Si H, Zhu L, Wu C, Sun Z (2007) Identification and fine mapping of a thermo-sensitive chlorophyll deficient mutant in rice (Oryza sativa L). Planta 226:785-795

Liu Y, He J, Chen Z, Ren X, Hong X (2010) ABA overly-sensitive 5 (ABO5), encoding a pentatricopeptide repeat protein required for cis-splicing of mitochondrial nad2 intron 3, is involved in the abscisic acid response in Arabidopsis. Plant J 63:749-765

Lobell DB, Schlenker W, Costa-Roberts J (2011) Climate trends and global crop production since 1980. Science 333:616-620

López-Juez E (2007) Plastid biogenesis, between light and shadows. J Exp Bot 58: $11-26$

Martinis SA, Plateau P, Cavarelli J, Florentz C (1999) Aminoacyl-tRNA synthetases: a family of expanding function. Mittelwihr, France, October 10-15, 1999. EMBO J 18:4591-4596

Moradi F, Ismail AM (2007) Responses of photosynthesis, chlorophyll fluorescence and ROS-scavenging systems to salt stress during seedling and reproductive stages in rice. Ann Bot 99:1161-1173

Mullet JE (1993) Dynamic regulation of chloroplast transcription. Plant Physiol 103:309-313

Murray MG, Thompson WF (1980) Rapid isolation of high molecular weight plant DNA. Nucleic Acids Res 8:4321-4325

Pak D, Kim Y, Burton ZF (2018) Aminoacyl-tRNA synthetase evolution and sectoring of the genetic code. Transcription 9:205-224

Peng S, Huang J, Sheehy JE, Laza RC, Cassman KG (2004) Rice yields decline with higher night temperature from global warming. Proc Natl Acad Sci U S A 101:9971-9975

Peng Y, Zou T, Li L, Tang S, Li Q, Zhang J, Chen Y, Wang X, Yang G, Hu Y (2019) Map-based cloning and functional analysis of YE1 in rice, which is involved in light-dependent chlorophyll biogenesis and photoperiodic flowering pathway. Int J Mol Sci 20:758

Qiu Z, Kang S, He L, Zhao J, Zhang S, Hu J, Zeng D, Zhang G, Dong G, Gao Z, Ren D, Chen G, Guo L, Qian Q, Zhu L (2017) The newly identified, heat-stress sensitive albino 1 gene affects chloroplast development in rice. Plant Sci 267:168-179

Qiu Z, Zhu L, He L, Chen D, Zeng D, Chen G, Hu J, Zhang G, Ren D, Dong G, Gao Z, Shen L, Zhang Q, Guo L, Qian Q (2019) DNA damage and reactive oxygen species cause cell death in the rice local lesions 1 mutant under high light and high temperature. New Phytol 222:349-365

Ren D, Yu H, Rao Y, Xu Q, Zhou T, Hu J, Zhang Y, Zhang G, Zhu L, Gao Z (2017) 'Two-floret spikelet' as a novel resource has the potential to increase rice yield. Plant Biotechnol J 16:351-353
Schimmel PR, Soll D (1979) Aminoacyl-tRNA synthetases: general features and recognition of transfer RNAs. Annu Rev Biochem 48:601-48.

Semenova GA (2004) Structural reorganization of thylakoid systems in response to heat treatment. Photosynthetica 42:521-527

Sugimoto H, Kusumi K, Noguchi K, Yano M, Yoshimura A, Iba K (2007) The rice nuclear gene, VIRESCENT 2, is essential for chloroplast development and encodes a novel type of guanylate kinase targeted to plastids and mitochondria. Plant J 52:512-527

Szymański M, Deniziak M, Barciszewski J (2000) The new aspects of aminoacyltRNA synthetases. Acta Biochim Pol 47:821-834

Thordal-Christensen H, Zhang Z, Wei Y, Collinge DB (2010) Subcellular localization of $\mathrm{H}_{2} \mathrm{O}_{2}$ in plants. $\mathrm{H}_{2} \mathrm{O}_{2}$ accumulation in papillae and hypersensitive response during the barley-powdery mildew interaction. Plant J 11:1187-1194

Triantaphylidès C (2008) Singlet oxygen is the major reactive oxygen species involved in photooxidative damage to plants. Plant Physiol 148:960-968

Ueno D, Koyama E, Kono I, Ando T, Yano M, Ma JF (2009) Identification of a novel major quantitative trait locus controlling distribution of $\mathrm{cd}$ between roots and shoots in rice. Plant Cell Physiol 50:2223-2233

Uwer U, Willmitzer L, Altmann T (1998) Inactivation of a glycyl-tRNA synthetase leads to an arrest in plant embryo development. Plant Cell 10:1277-1294

Wang WJ, Zheng KL, Gong XD, Xu JL, Huang JR, Lin DZ, Dong YJ (2017) The rice TCD11 encoding plastid ribosomal protein $\mathrm{s} 6$ is essential for chloroplast development at low temperature. Plant Sci 259:1-11

Wang Y, Wang C, Zheng M, Lyu J, Xu Y, Li X, Niu M, Long W, Wang D, Wang H, Terzaghi W, Wang Y, Wan J (2016) White panicle1, a Val-tRNA synthetase regulating chloroplast ribosome biogenesis in rice, is essential for early chloroplast development. Plant Physiol 170:2110-2123

Wellburn AR (1994) The spectral determination of chlorophylls a and b, as well as total carotenoids, using various solvents with spectrophotometers of different resolution. J Plant Physiol 144:307-313

Wu Z, Zhang X, He B, Diao L, Sheng S, Wang J, Guo X, Su N, Wang L, Jiang L, Wang C, Zhai H, Wan J (2007) A chlorophyll-deficient rice mutant with impaired chlorophyllide esterification in chlorophyll biosynthesis. Plant Physiol 145:29-40

Yamamoto Y, Aminaka R, Yoshioka M, Khatoon M, Komayama K, Takenaka D, Yamashita A, Nijo N, Inagawa K, Morita N, Sasaki T, Yamamoto Y (2008) Quality control of photosystem II: impact of light and heat stresses. Photosynth Res 98:589-608

Yang X, Li Y, Qi M, Liu Y, Li T (2019) Targeted control of chloroplast quality to improve plant acclimation: from protein import to degradation. Front Plant Sci 10:958

Yoo SC, Cho SH, Sugimoto H, Li J, Kusumi K, Koh HJ, Iba K, Paek NC (2009) Rice virescent3 and stripe 1 encoding the large and small subunits of ribonucleotide reductase are required for chloroplast biogenesis during early leaf development. Plant Physiol 150:388-401

Yu C, Wang L, Chen C, He C, Hu J, Zhu Y, Huang W (2014) Protoplast: a more efficient system to study nucleo-cytoplasmic interactions. Biochem Biophys Res Commun 450:1575-1580

Yuan H, Liu D (2012) Functional disruption of the pentatricopeptide protein SLG1 affects mitochondrial RNA editing, plant development, and responses to abiotic stresses in Arabidopsis. Plant J 70:432

Zhang JZ, Somerville CR (1997) Suspensor-derived polyembryony caused by altered expression of valyl-tRNA synthetase in the twn2 mutant of Arabidopsis. Proc Natl Acad Sci U S A 94:7349-7355

Zheng K, Zhao J, Lin D, Chen J, Xu J, Zhou H, Teng S, Dong Y (2016) The rice TCM5 gene encoding a novel deg protease protein is essential for chloroplast development under high temperatures. Rice 9:13

\section{Publisher's Note}

Springer Nature remains neutral with regard to jurisdictional claims in published maps and institutional affiliations. 